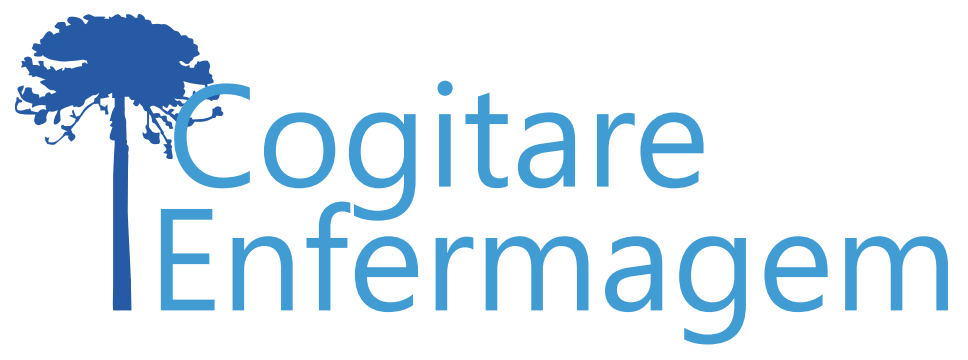

\title{
GESTÃO HOSPITALAR E GERENCIAMENTO EM ENFERMAGEM À LUZ DA FILOSOFIA LEAN HEALTHCARE
}

Thaís Oliveira da Silva", Livia Minuzzi Vieira², Tamires Souza Lemos ${ }^{3}$, Fernando Perdoná Sant'Anna ${ }^{4}$, Roberta Seron Sanches ${ }^{5}$, Maria Regina Martinez ${ }^{6}$

\section{RESUMO}

Este artigo objetivou refletir sobre a gestão hospitalar e o gerenciamento em enfermagem atrelados à filosofia Lean Healthcare. Concluiu-se que tanto os hospitais quanto o seu maior quantitativo de trabalhadores, a equipe de enfermagem, podem ser beneficiados com a aplicação dos conceitos Lean, no sentido de evitar desperdícios, agregar valor ao serviço e propiciar mais qualidade de assistência em saúde.

DESCRITORES: Administração Hospitalar; Gestão da Qualidade Total; Enfermagem; Economia da Enfermagem; Cuidados de Énfermagem.

COMO REFERENCIAR ESTE ARTIGO:

Silva TO da, Vieira LM, Lemos TS, Sant'Anna FP, Sanches RS, Martinez MR. Gestão hospitalar e gerenciamento em enfermagem à luz da filosofia lean healthcare. Cogitare enferm. [Internet]. 2019 [acesso em "colocar data de acesso, dia, mês abreviado e ano"]; 24. Disponível em: http://dx.doi.org/10.5380/ce.v24i0.60003.

Este obra está licenciado com uma Licença Creative Commons Atribuição 4.0 Internacional.

${ }^{1}$ Enfermeira. Doutoranda em Ciências. Universidade de São Paulo. Ribeirão Preto, SP, Brasil. $\left(\frac{)}{9}\right.$

${ }^{2}$ Discente de Enfermagem. Universidade Federal de Alfenas. Alfenas, MG, Brasil. $(9$

${ }^{3}$ Discente de Enfermagem. Universidade Federal de Alfenas. Alfenas, MG, Brasil. 0

${ }^{4}$ Discente de Medicina. Universidade Federal de Alfenas. Alfenas, MG, Brasil.

${ }^{5}$ Enfermeira. Doutora em Ciências. Docente de Enfermagem da Universidade Federal de Alfenas. Alfenas, MG, Brasil. $\bigcirc$

${ }^{6}$ Enfermeira. Doutora em Ciências. Docente de Enfermagem da Universidade Federal de Alfenas. Alfenas, MG, Brasil. $\bigcirc$ 


\section{HOSPITAL MANAGEMENT AND NURSING MANAGEMENT IN THE LIGHT OF THE LEAN PHILOSOPHY IN HEALTHCARE}

\section{ABSTRACT}

This article aimed to reflect on hospital management and nursing management based on the Lean Philosophy in Healthcare. It was concluded that hospitals and their most numerous health professionals, the nursing team, may benefit from the application of Lean concepts, in order to avoid waste, add value to the service and provide better health care.

DESCRIPTORS: Hospital management; Total Quality Management; Nursing; Nursing Economics; Nursing care.

\section{GESTIÓN HOSPITALARIA Y GERENCIAMIENTO EN ENFERMERÍA A LA LUZ DE LA FILOSOFIA LEAN HEALTHCARE}

\section{RESUMEN:}

Este artículo tuvo el objetivo de reflexionar acerca de la gestión hospitalaria y del gerenciamiento en enfermería viculados a la filosofía Lean Healthcare. Se concluyó que tanto los hospitales como su mayor cuantitativo de trabajadores, el equipo de enfermería, pueden ser beneficiados con la aplicación de los conceptos Lean, en lo que se refiere a evitar desperdicios, agregar valor al servicio y propiciar más cualidad de asistencia en salud.

DESCRIPTORES: Administración Hospitalaria; Gestión de la Cualidad Total; Enfermería; Economía de la Enfermería; Cuidados de Enfermería. 
Devido à complexidade da estrutura físico-funcional e da diversidade de recursos humanos e materiais especializados necessários ao seu funcionamento, o hospital requer um alto e constante investimento financeiro, o qual, muitas vezes, ultrapassa os lucros e gera desafios à sua sustentabilidade ${ }^{(1)}$.

Estratégias de gestão, como as contidas na filosofia Lean Healthcare, que venham ao encontro desses desafios, tendem a manter ou propiciar ações corretivas e de melhoria contínua que fortaleçam tanto a gestão hospitalar quanto o gerenciamento dos seus serviços $^{(2)}$.

Com o intuito de discorrer um pouco acerca desse contexto, este artigo objetivou refletir sobre a gestão hospitalar e o gerenciamento em enfermagem atrelados à filosofia Lean Healthcare.

A gestão hospitalar, em sua totalidade, envolve um conjunto de processos que são gerenciados em setores ou departamentos específicos. A fim de gerenciar efetivamente esses processos, bem como os recursos humanos e materiais envolvidos, o hospital deve mapear todas as suas atividades para ter um panorama global das necessidades de intervenção e dos pontos fortes já existentes ${ }^{(3)}$.

Uma das estratégias recentemente utilizadas na realidade hospitalar e de forma ainda incipiente na enfermagem e no Brasil para mapeamento e otimização de processos é a filosofia Lean Healthcare, que significa produção enxuta aplicada à saúde ${ }^{(3)}$.

Essa filosofia surgiu no Sistema Toyota de Produção (STP) e passou a ser difundida nos hospitais a partir de 2002, com o objetivo de diminuir ou excluir todo e qualquer desperdício relacionado aos processos, para gerar redução de custos, aumento de lucros e melhoria da qualidade do serviço prestado no hospital (2).

A produção enxuta carreia em si vários princípios, dentre eles, determinar o que é valor para o cliente; identificar o fluxo de valor, ou seja, a sequência de operações e atividades que agregam e não agregam valor ao processo produtivo; implantar fluxo contínuo, em que cada atividade é imediatamente passada à atividade seguinte, evitando gerar estoques e paradas; e desenvolver produção puxada, isto é, onde não for possível implantar fluxo contínuo, deve-se produzir somente quando o cliente requerer ${ }^{(4)}$. Além desses princípios, há um compromisso com a perfeição, cuja busca pela melhoria contínua gera possibilidades infinitas aos hospitais ${ }^{(5)}$.

Nesse sentido, a fim de evitar desperdícios e atender as necessidades do seu real cliente, o paciente, o hospital e o serviço de enfermagem devem definir as atividades que agregam valor; as que são necessárias, mas não agregam valor; e aquelas que não agregam valor ${ }^{(6)}$. As atividades que agregam valor tornam o serviço mais valioso para o cliente, por exemplo, quando o paciente é medicado pela equipe de enfermagem; as que são necessárias mas não agregam valor, não tornam o serviço mais valioso para o cliente, porém são necessárias, por exemplo, quando a medicação é preparada pela equipe de enfermagem para somente depois ser administrada; e as que não agregam valor, não tornam o serviço mais valioso ao cliente, e nem são necessárias, por exemplo, quando ocorre uma não gestão de estoque, a medicação tem a sua data de validade vencida ${ }^{(7)}$.

Aprofundando um pouco mais nos conceitos Lean, Ohno ${ }^{(8)}$, um executivo e crítico da Toyota, definiu sete categorias de desperdício que podem ser facilmente exemplificadas no setor saúde(5): Superprodução (Monitorizar um paciente excessivamente sem necessidade), Defeitos (Administrar medicação errada), Inventários Desnecessários (Longas esperas por resultados de exames), Processamento Inapropriado (Prescrever antibiótico para inflamação), Transporte Excessivo e Movimentação Excessiva (de pacientes ou medicamentos devido a um layout hospitalar não otimizado), Esperas (por um diagnóstico 
médico). E, complementando Ohno, sugiram ainda duas novas categorias de desperdício(9): a re-priorização, que pressupõe o início de uma nova tarefa antes que outra já iniciada esteja concluída, e a pouca utilização do talento das pessoas, utilizando-as como operadoras e não como trabalhadores especialistas em processos.

A filosofia Lean Healthcare tem sido utilizada em hospitais, ainda que de forma incipiente na realidade brasileira, para melhoria da gestão por processos e para a redução de desperdícios e custos ${ }^{(10)}$. Alguns exemplos, em grande parte internacionais, podem ser citados: um hospital norte americano reduziu o Lead Time (tempo de parada) do Fluxo de Paciente em 25\%, do transporte, em 75\%, e do tempo de espera, em 31\%; também em fluxos radiologia-centro cirúrgico, e nos processos de trabalho no setor de radiologia ${ }^{(5)}$.

Outro exemplo é de um hospital nos Estados Unidos da América que reduziu o tempo de envio de medicamentos da farmácia para os leitos de 4 horas para 12 minutos. O Virginia Mason Medical Center (EUA), usando ferramentas lean, aumentou a sua produtividade em $36 \%$ e reduziu seus estoques em $53 \%$. No ThedaCare Inc. (EUA), a média de dias que um paciente ficava no hospital passou de 6,3 dias para 4,9 dias e o custo de uma cirurgia coronariana caiu $22 \%$.

Dos profissionais que compõem o hospital, aqueles que fazem parte da equipe de enfermagem são os que estão em maior número e atuam na assistência direta ao cliente em todos os momentos de seu ciclo vital, desde o nascimento até a morte. Ressalta-se que o serviço de enfermagem contempla o atendimento hospitalar em suas 24 horas diárias de funcionamento e tem atuação em todas as especialidades da realidade hospitalar ${ }^{(1)}$.

Segundo a Organização Mundial de Saúde (OMS)(11), há grandes desafios relacionados a garantir sustentabilidade e equidade em saúde à população e, diante do seu relatório, do ano de 2016, surgiu a campanha Nursing Now (Enfermagem Agora), lançada em fevereiro de 2018, que afirma ser o profissional de enfermagem um dos mais aptos e mais capacitados ao enfrentamento dos desafios da saúde no século XX| ${ }^{(12)}$.

Nesse contexto, os enfermeiros são capacitados a articular gerência e assistência no ambiente hospitalar de forma centrada no cuidado, focando na melhoria da assistência e na qualidade do serviço prestado nas unidades ${ }^{(13)}$. Envolvendo-se de forma científica, política e humanizada, a enfermagem carrega em si grande potencial de mudança no perfil da saúde apresentado pela OMS ${ }^{(12)}$.

No entanto, o enfoque tradicional na realização das tarefas, como praticar a assistência de forma tecnicista, confeccionar escalas de pessoal e controlar materiais e equipamentos, ainda está enraizado no serviço de enfermagem, refletindo pouco envolvimento dos enfermeiros diretamente no gerenciamento do seu serviço, no gerenciamento em saúde e na gestão hospitalar como um todo(13).

Estar envolvido nos processos de gerenciamento hospitalar significa investir em competências que assegurem sustentabilidade financeira, qualidade do serviço prestado e segurança ao cliente. Por serem o maior quantitativo de trabalhadores no hospital e por terem formação crítica, reflexiva, política, científica, clínica e social, os enfermeiros são altamente capazes de liderar o gerenciamento dos processos hospitalares e do serviço de enfermagem com vistas a valorizar o seu serviço e aprimorar a assistência hospitalar ${ }^{(14)}$.

A filosofia Lean indica que o enfermeiro, com sua formação profissional, é altamente capaz de aprimorar o gerenciamento dos serviços hospitalares ${ }^{(13)}$. Embora na literatura haja um número incipiente de publicações sobre as práticas enxutas em saúde desenvolvidas ou lideradas pela enfermagem ${ }^{(14)}$, pesquisadores apostam que o envolvimento destes profissionais na execução de programas lean são primordiais para que a filosofia faça parte do hospital como um todo e seja realmente implantada, visto que grande parte das atividades diárias hospitalares são desenvolvidas por enfermeiros e técnicos de enfermagem ${ }^{(13)}$.

Alguns pesquisadores relacionam indicadores de melhoria de processos de trabalho em enfermagem após implantação de metodologias lean ${ }^{(14)}$, relatando diminuição de 
níveis de estresse a partir de padronização e nivelamento de trabalho; redução de cansaço envolvido, a partir de redução de lead time na execução de tarefas, retrabalhos, transportes excessivos, acúmulo de funções, infraestrutura inadequada e fluxo moroso nas rotinas de trabalho(10).

Diante desse contexto apresentado, pôde-se observar a importância e os resultados provenientes do uso da filosofia Lean Healthcare nos hospitais. Destarte, salienta-se que os processos de melhoria só são mapeados e implantados com o envolvimento de todos os colaboradores, desde os administradores até os profissionais que estão diretamente trabalhando nos setores, principalmente a equipe de enfermagem, que são a linha de frente no atendimento em saúde ${ }^{(14)}$.

Nesse sentido, Lean Healthcare tanto pode colaborar com a melhoria dos processos de trabalho em enfermagem, como pode contribuir em demasia com a instituição na qual a filosofia é utilizada, tendo como reflexo diminuição de custos hospitalares ${ }^{(10)}$, melhoria no gerenciamento de processos ${ }^{(3)}$, alcance de maiores níveis de qualidade hospitalar ${ }^{(1)}$ e segurança do paciente ${ }^{(11)}$.

\section{CONSIDERAÇÕES FINAIS}

A Filosofia Lean Healthcare associada à Gestão Hospitalar e ao Gerenciamento do Serviço de Enfermagem tende a possibilitar o aprimoramento dos processos a partir da redução de custos e desperdícios, com consequente geração de lucros, valorização do serviço prestado e alcance de mais qualidade no atendimento ao cliente, ao qual é atribuído o verdadeiro valor. Neste cenário, o profissional de enfermagem tem papel essencial e pode ter seu processo de trabalho aprimorado com a execução de programas lean.

\section{REFERÊNCIAS}

1. Mozachi N, Souza VHL. O Hospital- Manual do Ambiente Hospitalar. 4. ed. São Paulo: Direção Cultural; 2017.

2. Castilho V, Castro LC de, Couto AT, Maia FOM, Sasaki NY, Nomura FH, et al. Levantamento das principais fontes de desperdício de unidades assistenciais de um hospital universitário. Rev. esc. enferm USP. [Internet]. 2011 [acesso em 13 jun 2018]; 45(n.esp). Disponível em: http://dx.doi.org/10.1590/S008062342011000700012.

3. Collar RM, Shuman AG, Feiner S, McGonegal AK, Heidel N, Duck M, et al. Lean Management in Academic Surgery. J Am Coll Surg. [Internet]. 2012 [acesso em 13 jun 2018]; 215(6). Disponível em: https://doi.org/10.1016/j.jamcollsurg.2012.03.002.

4. Womack JP; Jones DT. A mentalidade enxuta nas empresas: elimine o desperdício e crie riqueza. 6. ed. Rio de Janeiro: Campus; 2004.

5. Bertani TM. Lean healthcare: Recomendações para implantações dos conceitos de produção enxuta em ambientes hospitalares [dissertação]. São Carlos (SP): Universidade de São Paulo; 2012.

6. Green J, Valentini A. A Guide to Lean Healthcare Workflows. [Internet] IBM Redbooks; 2016 [acesso em 14 jun 2018]. Disponível em: http://www.redbooks.ibm.com/redpapers/pdfs/redp5240.pdf.

7. Pinheiro B, Tortorella G. Uma análise qualitativa a partir do método Delphi das práticas enxutas e fatores críticos para implementação do LeanHealthcare. Iberoam. J. Ind. Eng. [Internet]. 2017 [acesso em 14 jun 2018]; 16(8). Disponível em: http://incubadora.periodicos.ufsc.br/index.php/IJIE/article/view/ v8n1611.

8. Ohno T. O Sistema Toyota de produção: além da produção em larga escala. Porto Alegre: Bookman; 1997. 
9. Amirahmadi F, Dalbello A, Gronseth D, Mccarthy J. Innovations in the Clinical Laboratory: An Overview of Lean Principles in the Laboratory. EUA: Mayo Clinic; 2007.

10. Correia PJN. O pensamento Lean na otimização da gestão do processo de faturação hospitalar: um estudo de caso [dissertação]. Viseu (Portugal): Universidade Católica Portuguesa; 2017.

11. Organização Mundial da Saúde (OMS). Defendendo a saúde em nome do desenvolvimento sustentável e da equidade: liderando pelo exemplo. Relatório Anual do Diretor da Repartição Sanitária Pan-Americana, OMS; 2016.

12. Gabassa VC. Lean healthcare: estratégia para a qualificação da gestão em saúde e enfermagem [dissertação]. São Carlos (SP): Universidade Federal de São Carlos; 2014.

13. Magalhães ALP, Erdmann AL, Silva EL da, Santos JLG dos. Lean thinking in health and nursing: an integrative literature review. Rev. Latino-Am. Enfermagem. [Internet]. 2016 [acesso em 14 jun 2018]; 24. Disponível em: http://dx.doi.org/10.1590/1518-8345.0979.2734.

14. International Council of Nurses. Nursing Now. [Internet]. 2018 [acesso em 13 jun 2018]. Disponível em: http://www.icn.ch/what-we-do/Nusing-Now/.

Recebido: 18/06/2018

Finalizado: 14/03/2019

\section{Autor Correspondente:}

Thaís Oliveira da Silva

Universidade de São Paulo

Av. dos Bandeirantes, 3900 - 14040-902 - Ribeirão Preto, SP, Brasil

E-mail: thaisoliveirasilva10@gmail.com

\section{Contribuição dos autores:}

Contribuições substanciais para a concepção ou desenho do estudo; ou a aquisição, análise ou interpretação de dados do estudo - TOS, LMV, TSL, FPSA

Elaboração e revisão crítica do conteúdo intelectual do estudo - TOS, RSS, MRM

Aprovação da versão final do estudo a ser publicado - TOS, LMV, TSL, FPSA, RSS, MRM

Responsável por todos os aspectos do estudo, assegurando as questões de precisão ou integridade de qualquer parte do estudo - TOS, MRM 